\title{
Slipped capital femoral epiphysis in adults: case report and review of literature
}

\author{
C.C. Macía-Villa', I. Sanchez-Lite ${ }^{2}$, J. Medina-Luezas ${ }^{1}$ \\ ${ }^{1}$ Department of Rheumatology, Clinical University Hospital of Valladolid, Valladolid, Spain; \\ ${ }^{2}$ Department of Radiology, Muscleskeletal section, Clinical University Hospital of Valladolid, Valladolid, Spain
}

\begin{abstract}
SUMMARY
Slipped capital femoral epiphysis (SCFE) mainly affects overweight prepubertal children. It is usually idiopathic, but endocrinological diseases are proposed as the main cause. SCFE occurs before the closing of the femoral physis, which generally occurs at 18 years in males and 16 years in females, therefore it is considered a children's disease. However, there have been several reports of adults with SCFE and some familial cases. We present a case of bilateral SCFE in a 47 years old female with possible relationship with inhaled corticosteroids, and for the first time we collect and analyze all published cases in adults.
\end{abstract}

Key words: Slipped; epyphisis; femur; adult; corticosteroids; bone.

Reumatismo, 2016; 68 (1): 40-47

\section{INTRODUCTION}

lipped capital femoral epiphysis (SCFE) is one of the most frequent hip disorders in children. SCFE is due to the displacement of the epiphysis (femoral head, that keeps its location in the acetabulum) relative to the metaphysis (femoral neck) and shaft at the the physis level (1, 2 ). Most SCFE patients are younger than 18 years old because proximal femoral physis fuses at the age of 18 in boys and 16 in girls. However, it can also appear in adults with a delayed skeletal maturation. Anything able to decrease the growth plate resistance or to maintain the epiphysis opened might result in SCFE at any age.

The physiologic age when SCFE occurs is less variable than the chronologic age (3), which is called the narrow bone age window. This suggests that SCFE only has the opportunity to appear while the physis is still opened, and this depends on the bone age (or bone health) more than on the chronological age. At cellular level, the physis in these cases shows loss of regular longitudinal cell column formation in the cartilage and increased intercellular matrix. The damage in SCFE occurs between hypertrophy zones and provisional ossification zones, although it can extend towards the germinal zone or into the metaphysis (4).

Clinical expression of SCFE is usually groin and limp pain, with decreased rotations (mainly external) on physical examination (5). However there are several reports of asymptomatic cases, as it was demonstrated in a study in 2072 healthy Norwegian young people (18-20 years old) that found $6.6 \%$ cases of silent radiological SCFE (6). The reported incidence is variable depending on the countries, oscillating between 0.2 and 24.5:100,000 children 8 to 15 years old $(1,3,5)$, but this number may underestimate the real incidence due to silent forms (7). SCFE is more frequent during the adolescent growth spur that happens to an average age of 13.5 years in boys and 12 years in girls. It is more prevalent in non-Caucasian males, and some series describe a seasonal variation in the incidence, being higher in spring and summer.

SCFE is frequently bilateral, reaching $50 \%$ of cases in some series. In unilateral cases, the age of presentation is usually younger, left hip is affected twice as often than the right, and an increased risk of contralateral damage appears in the next 18 months (3, $8)$. It is important to always check the contralateral hip as some series describe $40 \%$ prevalence of asymptomatic slips in this 
location (6). The only definite treatment is surgery, and most symptomatic cases need a total hip replacement.

The etiology of SCFE is unknown, but there are several disorders that have been related with its presentation and are summarized in Table I. Overweight with a body mass index higher than a $95 \%$ is reported in $63-80 \%$ of children with SCFE, and it has demonstrated to change the normal hip biomechanics $(1,5,9)$.

In post adolescence, endocrinopathy is the most common cause of SCFE, mainly hypothyroidism and hypogonadism that produce delayed fusion of the epiphysis (10). Several hypophysis dysfunctions have been associated with SCFE: Simmonds-Seehan disease and other causes of hypopituitarism (craniopharyngiomas, optic gliomas or chronic subdural hematomas), pinealomas and growth hormone $(\mathrm{GH})$ pathologies. $\mathrm{GH}$ physiologically decreases the strength of the physis affecting the cells of the epiphyseal ossification center, explaining the cases of SCFE during GH treatment or pathologies with increased levels like acromegalic gigantism. Only elevated $\mathrm{GH}$ has been related with SCFE, there are any reported cases with isolated GH deficiency. In panhypopituitarism a $\mathrm{GH}$ decrease can be seen, but the effect of the other pituitary hormones seems to prevail $(1,2,4)$. In chronic renal failure the probability of epiphyseal separation is increased due to metabolic acidosis, secondary hyperparathyroidism and deficient vitamin D activation, that decrease bone mass and mineralization with changes in the cartilaginous plate of proximal femur. Calcitriol also has a direct action on epiphyseal chondrocytes, and some authors suggest that the seasonal variation of SCFE can be related to a decrease in vitamin $\mathrm{D}$ after several months without sunlight $(5,11)$. There is probably an hereditary factor involved in this disease: a decreased expression of collagen type II and proteoglycans has been reported in some patients, and SCFE has been described in Frolich's, Marfan's, Klinefelter's and Down's syndromes (12). Although the relationship between SCFE and glucocorticoids (endogenous or exogenous) has not been demonstrated yet (5), their skeletal effects on bone are widely known being the most common iatrogenic cause of secondary osteoporosis.

Regardless of the previously described associations with SCFE, the implication of these diseases remains controversial and diverse factors may play a role in each patient. The typical case normally appears in the absence of consistent biomechanical, biochemical or metabolic abnormalities (12).

We present an atypical case of SCFE in a female adult, and we collect and review all the adult SCFE cases published until the date.

Table I - Principal causes of slipped femoral capital epiphysis.

\begin{tabular}{|l|l|}
\hline \multirow{4}{*}{ Mechanical factors } & - Overweight \\
& - Traumas \\
& - Deeper acetabula \\
& - Coxa vara \\
& - Femoral and acetabular retroversion \\
\hline \multirow{3}{*}{ Hormonal factors } & - Hypophysis dysfunction \\
& - Hypothyroidism \\
& - Hypogonadism \\
& - Chronic renal failure \\
& - Calcitriol deficit \\
& - Other endocrine dysfunctions: hyperparathyroidism, adiposogenital \\
& syndrome, malnutrition \\
\hline Genetic factors & - Decreased expression of collagen type II and proteoglycans \\
\hline Toxics and drugs & - Frolich's, Marfan's, Klinefelter's and Down's syndromes \\
\hline Idiopathic & - Radiation and chemotherapy, especially actinomycin D \\
\hline
\end{tabular}




\section{CASE REPORT}

We present the case of a 47 years old Caucasian female with mild dyslipidemia (dietetic treatment), intrinsic asthma treated with inhaled corticosteroids for the last 6 years (fluticasone $500 \mathrm{mcgr}$ bid: equivalent to $2000 \mathrm{mcgr} /$ day of beclomethasone) and smoker of 20 cigarettes/day. Her menopause began two menopause two years ago and has not received hormone supplements. Previously asymptomatic, in August 2014 she developed without obvious cause a disabling left groin pain that became bilateral in a few days. Hip x-rays (Figure 1A) showed subtle lineal high-density images in both femoral necks, mainly on the left side. She was referred to Traumatology and Rheumatology departments. At clinical examination she was able to walk with bilateral groin pain, no leg length differences were noted, the left hip flexion was limited to $45^{\circ}$, and internal and external bilateral rotations to $15^{\circ}$. The study was amplified in the next months with more imaging tests (Figures 1B, 2, 3 and 4) and diagnosis of bilateral SCFE was made. A whole body Tc99 scintigraphy showed pathological findings only in hips, bone densitometry values were normal at lumbar spine, neck and total hip, and an exhaustive laboratory study including liver and renal function test, blood cell count, acute phase reactants, blood and urine calcium and phosphorus, alkaline phosphatase, bone turnover markers, celiac disease antibodies and hormones (parathormone, sex hormones, prolactine, cortisol, ACTH and somatomedine IGF-I) was normal except for severe vitamin D deficiency (25 hydroxycholecalciferol levels $7.74 \mathrm{ng} / \mathrm{mL}$ ) and menopausal status. She had failed to symptomatic treatment prescribed by her General Practitioner. The

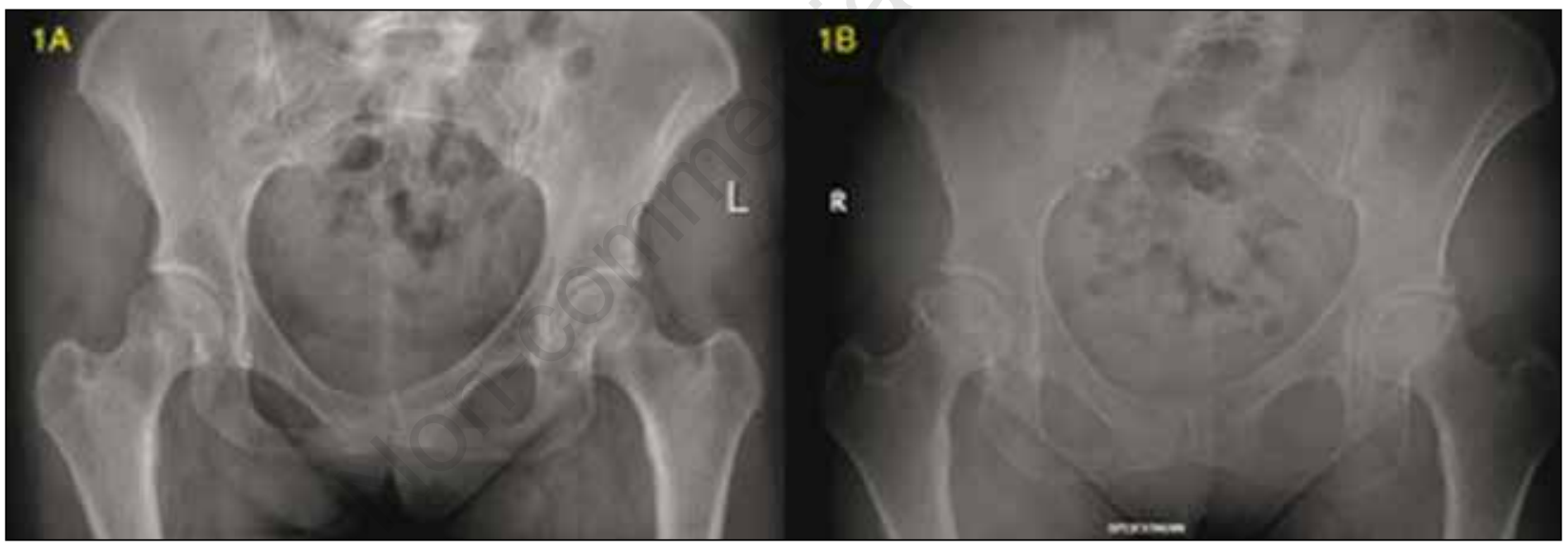

Figure 1 - Anteroposterior pelvis plain radiographs. A) At the moment of beginning of pain symptoms, minimal high density lineal images in both femoral necks, mainly on the left one. B) 6 months after Figure 1A, bilateral epiphyseal fracture with minimal displacement.

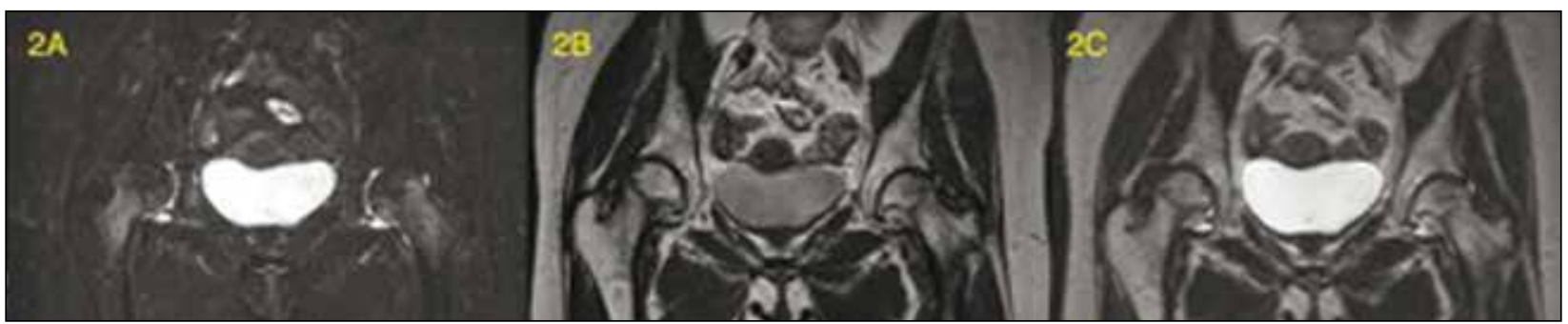

Figure 2 - Magnetic resonance images (MRI) showing results 3-month after Figure 1A. A) Coronal short tau inversion recovery MR image: extensive bone marrow edema in both femoral heads; $B$ and C) Coronal T1-weighted MR image and coronal T2-weighted MR image sequences, respectively: fracture lines in femoral epiphyses. 


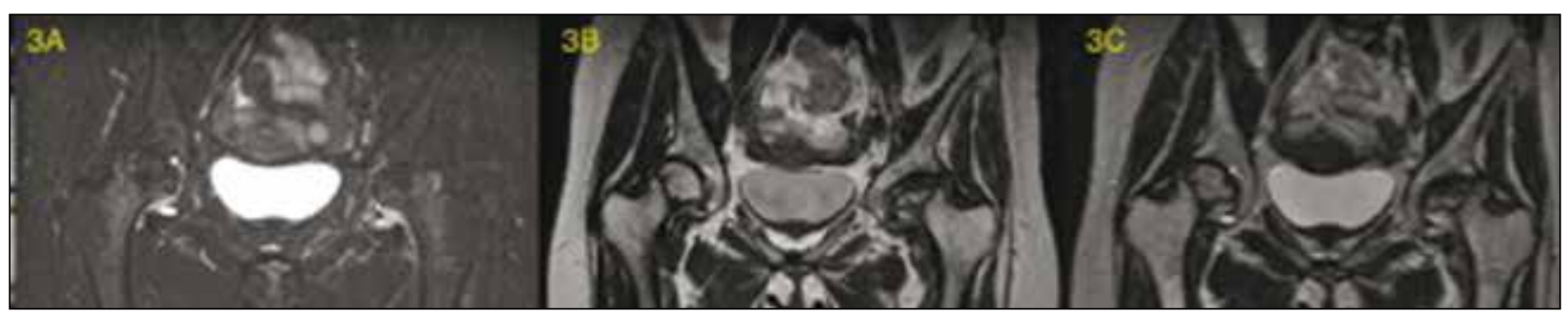

Figure 3 - Magnetic resonance images (MRI) showing results 7-month after Figure 1A. Fracture lines in both femoral heads with mild displacement, decreased bone marrow edema compared with Figure 2, and collapse and secondary osteonecrosis in left femoral head. Panels A, B and C are respectively coronal short tau inversion recovery MR image, coronal T1-weighted MR image and coronal T2-weighted MR image sequences.

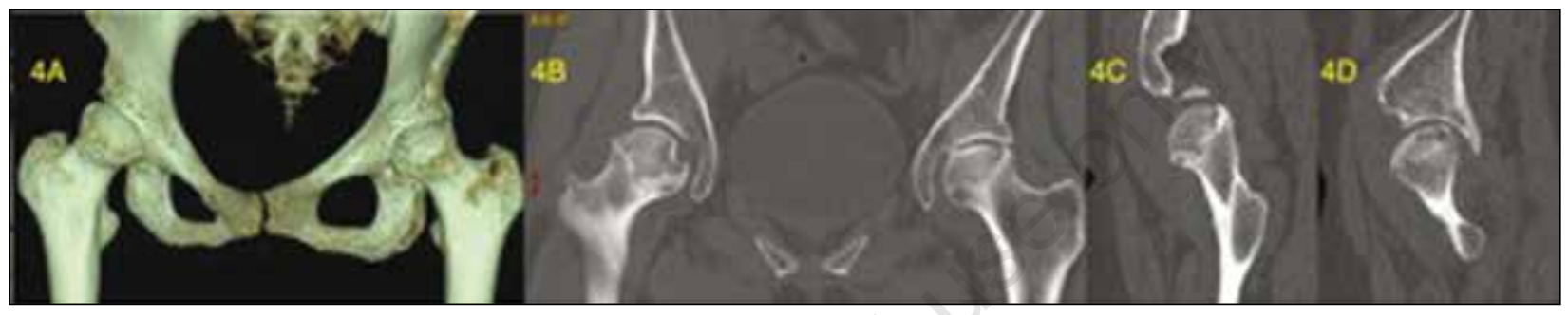

Figure 4 - Computed tomographic images 7-month after Figure 1A. A) 3D image; B) coronal view; C) sagittal right hip view; and $D$ sagittal left hip view. Fracture lines in both femoral epiphyses with mild displacement and collapse signs in left femoral head.

pain mildly improved with walking restriction with wheelchair and crutches and the patient was discharged at home. Vitamin D supplements were prescribed with normalization of serum levels 3 months later. At the moment of publication, the patient has recently undergone surgery with a left total hip replacement.

\section{DISCUSSION}

Some patients undergo slippage at atypical ages when physis are supposed to be already closed. This situation, linked to the fact that many cases are asymptomatic and sometimes an unexpected radiological finding, makes the real prevalence of adult SCFE probably underestimated. Moreover, for some authors most cases of premature hip osteoarthritis are a sequel of known (and unknown) hip disorders as hip dysplasia, Legg-Calvé-Perthes, and also SCFE (13). Sometimes, the etiology of this atypical SCFE cases is found, but there are several idiopathic cases that leave us an unanswered question: are adult SCFE cases a childhood disease with a delayed diagno- sis, or are they acute slippings in an adult non-closed physis?

All previously reported series of SCFE set the upper age limit at 18 years assuming that this is the normal limit of physiological physis closure. Only $\mathrm{Hu} \mathrm{MH}$ and colleagues (8) searched for SCFE cases in adults older than 20 years between 1960 and 2009. We decided to do a non previously published review of SCFE cases in people older than 18 years: adult cases (14-44) searched in PubMed up to June 30, 2015 with keywords slipped, femoral, epiphysis, head (mainly searching for large series with possible adult cases) and same keywords adding adult (searching exclusively adult cases). References of retrieved articles were also reviewed. Inconclusive or incompletely described cases were rejected. Results are shown in Table II. Since 1940 (first report founded) we have found 60 cases, and 136 asymptomatic radiological SCFE in the Norwegian healthy cohort 18-20 years old (6). Excluding this cohort, there are 23 idiophatic cases, 17 secondary to hypophyseal abnormalities, 7 secondary to unspecified endocrine disorders, 5 re- 
Table II - Slipped capital femoral epiphysis cases published until 2015 in people equal or older than 19 years old at time of diagnosis. In familial studies age is usually not provided, all cases of the table are reported as mother, father or similar. Inconclusive or incompletely described cases have been discarded.

\begin{tabular}{|c|c|c|c|c|c|}
\hline Reference & Year & $\begin{array}{l}\text { Type } \\
\text { of report }\end{array}$ & $\begin{array}{l}\text { Number } \\
\text { of cases }\end{array}$ & $\begin{array}{l}\text { Age of diagnosis } \\
\text { (years) }\end{array}$ & Cause \\
\hline Thrap-Meyer (14) & 1940 & Familial & 1 & Unknown, father & Unknown \\
\hline Moore (15) & 1945 & Case & 1 & 21 & Traumatic \\
\hline Irwin (16) & 1946 & Familial & 1 & Unknown, father & Unknown \\
\hline Lofgren (17) & 1953 & Case & 2 & 20 and 35 & Hypophyseal abnormalities \\
\hline Farrow (18) & 1953 & Case & 1 & 26 & Simmond's disease \\
\hline Burrows (19) & 1957 & Serie & 1 & 41 & Pituitary hypogonadism \\
\hline Epps (20) & 1963 & Case & 1 & 22 & Hypothyroidism \\
\hline Goldman (21) & 1963 & Case & 1 & 27 & Hypopituitarism and gigantism \\
\hline Sarver (22) & 1964 & Case & 3 & 20,27 and 32 & Functional hypopituitarism and giantism \\
\hline Rennie (23) & 1967 & Familial & 2 & Unknown, father and uncle & Unknown \\
\hline Zimmerman (24) & 1967 & Case & 2 & 20 and 29 & Hypopituitarism \\
\hline Primiano (25) & 1971 & Case & 1 & 19 & Hypogonadism due to Klinefelter's syndrome \\
\hline Kelsey (26) & 1971 & $\begin{array}{l}\text { National } \\
\text { serie }\end{array}$ & 3 & $\begin{array}{l}\text { Two cases: } 19 \text { and } 22 \\
\text { One case: } 19\end{array}$ & $\begin{array}{l}\text { Unknown, both mentally and physically retarded } \\
\text { Steroid therapy for bronchial asthma }\end{array}$ \\
\hline Strunz (27) & 1972 & Case & 1 & 51 yo & Panhypopituitarism \\
\hline Heatley (28) & 1976 & Case & 2 & 19 and 27 yo & Intracranial tumors causing hypogonadism \\
\hline Al-Aswad (29) & 1978 & Case & 1 & 35 & Hypothyroidism \\
\hline Goldman (30) & 1978 & Case & 1 & 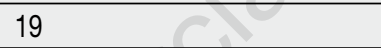 & Renal osteodystrophy \\
\hline Hennessy (31) & 1982 & Case & 1 & 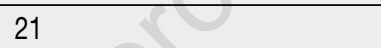 & Hypothyroidism \\
\hline Rennie (32) & 1982 & Familial & 3 & Unknown: father, aunt and uncle & Unknown \\
\hline McAfee (12) & 1983 & Case & 2 & $\begin{array}{l}19 \\
26\end{array}$ & $\begin{array}{l}\text { Radiation for sarcoma } \\
\text { Panhypopituitarism }\end{array}$ \\
\hline Hägglund (33) & 1986 & Familial & 2 & Unknown. 2 cases in fathers & Unknown \\
\hline Cooperman (7) & 1992 & $\begin{array}{l}\text { Post } \\
\text { mortem }\end{array}$ & 7 & $\begin{array}{l}\text { Unknown age of onset, only } \\
\text { data of ages of death (26-68) }\end{array}$ & Unknown \\
\hline Wells (34) & 1993 & Case & 1 & Unknown, older than 20 & Craniopharyngioma with panhypopituitarism \\
\hline Montskó (35) & 1995 & Familial & 3 & 21,24 and 66 & Unknown \\
\hline Feidy (36) & 1997 & Case & 1 & 24 & Acromegalic gigantism \\
\hline Moreira (37) & 1998 & Familial & 1 & 40 yo & Unknown \\
\hline Diwan (38) & 1998 & Familial & 1 & Unknown, mother & Unknown \\
\hline De Silva (39) & 2000 & Case & 1 & 80 yo & Idiopathic \\
\hline Noguchi (40) & 2002 & $\begin{array}{l}\text { National } \\
\text { serie }\end{array}$ & 7 & Unknown, older than 20 & $\begin{array}{l}\text { All with unspecified endocrine disorders } \\
\text { (mentioned hypopituitarism and hypothyroidism) }\end{array}$ \\
\hline Huang (41) & 2007 & Case & 1 & 23 & Craniopharyngioma with panhypopituitarism \\
\hline Nourbakhsh (42) & 2008 & Case & 1 & 24 & Hypothyroidism \\
\hline Brady (10) & 2010 & Case & 1 & 22 & Pituitary tumour with panhypopituitarism \\
\hline $\mathrm{Hu}(8)$ & 2011 & Case & 1 & 29 & Craniopharyngioma with panhypopituitarism \\
\hline Lehmann (43) & 2012 & $\begin{array}{l}\text { Arthroplasty } \\
\text { register }\end{array}$ & 1 & 24 & Unknown \\
\hline Lehmann (6) & 2013 & $\begin{array}{l}\text { National } \\
\text { serie }\end{array}$ & 136 & $\begin{array}{l}\text { Cohort of } 2072 \text { health } \\
\text { Norweigans } 18-20 \\
\text { Found x-rays compatible with } \\
\text { asymptomatic SCFE in } 6.6 \% \\
\text { (136 cases) }\end{array}$ & Unknown \\
\hline Marquez (44) & 2014 & Case & 1 & 28 & Hypothyroidism \\
\hline
\end{tabular}

SCFE, slipped capital femoral epiphysis. 
lated to hypothyroidism, 4 hypogonadism cases, and isolated case reports of trauma, renal osteodystrophy, post radiation, and asthma corticotherapy. This distribution matches with most frequent SCFE etiology in children: idiopathic and endocrine. Eight reports are family cases, mostly asymptomatic adult SCFE cases found in children relatives with symptomatic SCFE. Specifying the age of diagnosis in this category of studies is difficult, as frequently cases are reported in terms of family relationship (mother, father, uncle). Some authors postulate that there is probably a hereditary factor involved in SCFE, maybe in collagen type II and proteoglycans but this has not been clearly demonstrated, and there are several family reports without pathologic causes or background. There is also a post mortem study ${ }^{7}$ with age of death between 26-68 years old that found seven unknown SCFE cases. Finally there are three national series of Norway (6), Connecticut and Southwestern United States (26) and Japan (40), and an arthroplasty register (43).

Our case is not the first case of adult SCFE with previous normal hip x-ray. De Silva and colleagues (39) reported an 80 year-old man with previous radiologically closed epyphisis who later developed an idiopathic SCFE (histology excluded malignancy, osteomalacia and avascularity). We propose that a normal $\mathrm{x}$-ray in adults does not exclude microscopic physys pathology. Our case is the second report with a previous exposure to inhaled corticosteroids for asthma (26), but the time of exposure is not given. Oral glucocorticoids increase bone resorption, decrease bone formation and disrupt bone remodeling regulation resulting in a rapid loss of bone mineral density and bone quality even at doses as low as $2.5 \mathrm{mg}$ of prednisolone per day or equivalent for more than 3 months (45). Studies focused on the bone effect of inhaled corticosteroids show disparate results. A Cochrane systematic review (46), a retrospective cohort (47) and another study (48) found no evidence of bone mineral density loss, bone turnover or vertebral fractures in patients receiving chronic inhaled corticosteroids. On the contrary, a meta-analysis
(49) found a $12 \%$ increase in non-vertebral fractures and two other studies (50, 51) showed lower bone mineral density in these patients. A recent evaluation of publications in this topic by FRAX® group suggests an excess risk of fractures in those treated with high doses: $1600 \mathrm{mcgr} / \mathrm{d}$ of beclomethasone equivalent or greater (52). Overall there is no consensus, but data are consistent with a dose related decrease in bone mass and increased fracture risk in patients receiving long-term moderate to high dose-inhaled corticosteroids. In our case this is the most likely cause of SCFE we have found, although we cannot rule out the additive effect of accelerated bone loss related to recent menopause. The other pathological finding, vitamin D deficiency, can be explained by long rest at home and lack of exposure to sun after the beginning of SCFE symptoms.

\section{CONCLUSIONS}

SCFE is mainly a children's disease but it is also possible at older and atypical ages when physis are supposed to be closed. Although it is mandatory to rule out an underlying disease that can explain this lack of physiological consolidation, idiophatic cases prevail both in children and adults. This is the first review in literature of adults older than 18 years with SCFE, with 60 published cases since 1940 and 136 x-rays findings in a healthy cohort. In our case, we propose inhaled corticosteroids as the possible etiology with the exceptional finding of the absence of unclosed femoral physys in the initial hip x-ray interpreted as the presence of physis pathology at a microscopic level.

Conflict of interest: the authors declare no potential conflict of interest.

\section{REFERENCES}

1. Martínez-Álvarez S, Martínez-González C, Miranda Gorozarri C, et al. [Slipped capital femoral epiphysis]. Rev Esp Cir Ortopédica Traumatol. 2012; 56: 506-14. [Article in Spanish] 
2. Witbreuk M, van Kemenade FJ, van der Sluijs JA, et al. Slipped capital femoral epiphysis and its association with endocrine, metabolic and chronic diseases: a systematic review of the literature. J Child Orthop. 2013; 7: 213-23.

3. Loder RT, Skopelja EN. The epidemiology and demographics of slipped capital femoral epiphysis. ISRN Orthop. 2011; 2011: 486512.

4. Ogden JA, Southwick WO. Endocrine dysfunction and slipped captial femoral epiphysis. Yale J Biol Med. 1977; 50: 1-16.

5. Peck D. Slipped capital femoral epiphysis: diagnosis and management. Am Fam Physician. 2010; 82: 258-62.

6. Lehmann TG, Engesæter IØ, Laborie LB, et al. Radiological findings that may indicate a prior silent slipped capital femoral epiphysis in a cohort of 2072 young adults. Bone $\mathrm{Jt} \mathrm{J}$. 2013; 95-B: 452-8.

7. Cooperman DR, Charles LM, Pathria M, et al. Post-mortem description of slipped capital femoral epiphysis. J Bone Joint Surg Br. 1992; 74: 595-9.

8. Hu M-H, Jian Y-M, Hsueh Y-T, et al. Slipped capital femoral epiphysis in an adult with panhypopituitarism. Orthopedics 2011; 34: 222.

9. Novais EN, Millis MB. Slipped capital femoral epiphysis: prevalence, pathogenesis, and natural history. Clin Orthop. 2012; 470: 3432-8.

10. Brady RL, Price A. Delayed-onset slipped capital femoral epiphysis: case report of association with pituitary tumor. Am J Orthop Belle Mead NJ. 2010; 39: 137-40.

11. Jingushi S, Hara T, Sugioka Y. Deficiency of a parathyroid hormone fragment containing the midportion and 1,25-dihydroxyvitamin D in serum of patients with slipped capital femoral epiphysis. J Pediatr Orthop. 1997; 17: 216-9.

12. McAfee PC, Cady RB. Endocrinologic and metabolic factors in atypical presentations of slipped capital femoral epiphysis. Report of four cases and review of the literature. Clin Orthop. 1983; 180: 188-97.

13. Zilkens C, Bittersohl B, Jäger M, et al. Significance of clinical and radiographic findings in young adults after slipped capital femoral epiphysis. Int Orthop. 2011; 35: 1295-301.

14. Thrap-Meyer A. Epiphysiolisis capitis femoris in two generations: casuistic report. Acta Orthop Scand. 1940; 11: 1-10.

15. Moore R. Asceptic necrosis of the capital femoral epiphysis following adolescent epiphysiolisis. Surg Gynecol Obstet. 1945; 80: 199-204.

16. Irwin CG. Unilateral adolescent coxa vara. J Bone Joint Surg Br. 1946; 28: 653.

17. Lofgren L. Slipping of the upper femoral epiphysis, signs of endocrine disturbance, size of sella turcica and two illustrative cases of simultaneous slipping of the upper femoral epiphysis and tumour of the hypophysis. Acta Chir Scand. 1953; 106: 153-65.
18. Farrow R. Displacement of the upper femoral epiphysis in a man of twenty-six years suffering from Simmonds's disease following a head injury. J Bone Joint Surg Br. 1953; 35-B: 432-3.

19. Burrows HJ. Slipped upper femoral epiphysis; characteristic of a hundred cases. J Bone Joint Surg Br. 1957; 39-B: 641-58.

20. Epps CH Jr, Martin ED. Slipped capital femoral epiphysis in a sexually mature myxedematous female. JAMA 1963; 183: 287-9.

21. Goldman JK, Cahill GF, Thorn GW. Gigantism with hypopituitarism. Am J Med. 1963; 34: 407-16.

22. Sarver ME, Sabeh G, Fetterman GH, et al. Fractional hypopituitarism with giantism and normal sella turcica. N Engl J Med 1964; 271 : 1286-9.

23. Rennie AM. Familial slipped upper femoral epiphysis. J Bone Joint Surg Br. 1967; 49: 535-9.

24. Zimmerman TS, White MG, Daughaday WH, Goetz FC. Hypopituitarism with normal or increased height. Report of two cases, with measurement of plasma growth hormone levels. Am J Med 1967; 42: 146-50.

25. Primiano GA, Hughston JC. Slipped capital femoral epiphysis in a true hypogonadal male (Klinefelter's mosaic XY-XXY). A case report. J Bone Joint Surg Am. 1971; 53: 597601.

26. Kelsey JL. The incidence and distribution of slipped capital femoral epiphysis in Connecticut. J Chronic Dis. 1971; 23: 567-78.

27. Strunz P. [Epiphysiolysis of the femur head in a 51-year-old patient with panhypopituitarism]. Beitr Zur Orthop Traumatol. 1972; 19: 231-6. [Article in German]

28. Heatley FW, Greenwood RH, Boase DL. Slipping of the upper femoral epiphyses in patients with intracranial tumours causing hypopituitarism and chiasmal compression. J Bone Joint Surg Br. 1976; 58: 169-75.

29. Al-Aswad BI, Weinger JM, Schneider AB. Slipped capital femoral epiphysis in a 35-yearold man (a case report). Clin Orthop. 1978; 134: 131-4.

30. Goldman AB, Lane JM, Salvati E. Slipped capital femoral epiphyses complicating renal osteodystrophy: a report of three cases. Radiology 1978; 126: 333-9.

31. Hennessy MJ, Jones KL. Slipped capital femoral epiphysis in a hypothyroid adult male. Clin Orthop. 1982; 165: 204-8.

32. Rennie AM. The inheritance of slipped upper femoral epiphysis. J Bone Joint Surg Br. 1982; 64: $180-4$

33. Hägglund G, Hansson LI, Sandström S. Familial slipped capital femoral epiphysis. Acta Orthop Scand. 1986; 57: 510-2.

34. Wells D, King JD, Roe TF, Kaufman FR. Review of slipped capital femoral epiphysis as- 
sociated with endocrine disease. J Pediatr Orthop. 1993; 13: 610-4.

35. Montskó P, de Jonge T. Slipped capital femoral epiphysis in 6 of 8 first-degree relatives. Acta Orthop Scand. 1995; 66: 511-2.

36. Feydy A, Carlier RY, Mompoint D, et al. Bilateral slipped capital femoral epiphysis occuring in an adult with acromegalic gigantism. Skeletal Radiol. 1997; 26: 188-90.

37. Moreira JF, Neves MC, Lopes G, Gomes AR. Slipped capital femoral epiphysis. A report of 4 cases occurring in one family. Int Orthop. 1998; 22: 193-6.

38. Diwan A, Diamond T, Clarke R, et al. Familial slipped capital femoral epiphysis: a report and considerations in management. Aust N Z J Surg 1998; 68: 647-9.

39. De Silva RJ, Vince AS, Nolan JF. Acute slipped capital femoral epiphysis in the eightieth year of life: a case report. Injury 2000; 31: 390-3.

40. Noguchi Y, Sakamaki T, Multicenter Sutdy Commitee of the Japanese Pediatric Orthopaedic Association. Epidemiology and demographics of slipped capital femoral epiphysis in Japan: a multicenter study by the Japanese Paediatric Orthopaedic Association. J Orthop Sci Off J Jpn Orthop Assoc. 2002; 7: 610-7.

41. Huang K-C, Hsu RW-W. Slipped capital femoral epiphysis in a 23-year-old man - a case report. Acta Orthop. 2007; 78: 696-7.

42. Nourbakhsh A, Ahmed HA, McAuliffe TB, Garges KJ. Case report: bilateral slipped capital femoral epiphyses and hormone replacement. Clin Orthop. 2008; 466: 743-8.

43. Lehmann TG, Engesaeter IØ, Laborie LB, et al. Total hip arthroplasty in young adults, with focus on Perthes' disease and slipped capital femoral epiphysis: follow-up of 540 subjects reported to the Norwegian Arthroplasty Register during 1987-2007. Acta Orthop. 2012; 83: 159-64.
44. Marquez D, Harb E, Vilchis H. Slipped capital femoral epiphysis and hypothyroidism in a young adult: a case report. J Med Case Reports 2014; 8: 336.

45. Buehring B, Viswanathan R, Binkley N, Busse W. Glucocorticoid-induced osteoporosis: an update on effects and management. J Allergy Clin Immunol. 2013; 132: 1019-30.

46. Jones A, Fay JK, Burr M, et al. Inhaled corticosteroid effects on bone metabolism in asthma and mild chronic obstructive pulmonary disease. Cochrane Database Syst Rev. 2002; 1: CD003537.

47. van Staa TP, Leufkens HG, Cooper C. Use of inhaled corticosteroids and risk of fractures. $\mathbf{J}$ Bone Miner Res. 2001; 16: 581-8.

48. Herrala J, Puolijoki H, Impivaara O, et al. Bone mineral density in asthmatic women on high-dose inhaled beclomethasone dipropionate. Bone 1994; 15: 621-3.

49. Weatherall M, James K, Clay J, et al. Doseresponse relationship for risk of non-vertebral fracture with inhaled corticosteroids. Clin Exp Allergy 2008; 38: 1451-8.

50. Packe GE, Douglas JG, McDonald AF, et al. Bone density in asthmatic patients taking high dose inhaled beclomethasone dipropionate and intermittent systemic corticosteroids. Thorax 1992; 47: 414-7.

51. Wong CA, Walsh LJ, Smith CJ, et al. Inhaled corticosteroid use and bone-mineral density in patients with asthma. Lancet Lond Engl. 2000; 355: 1399-403.

52. Leib ES, Saag KG, Adachi JD, et al. Official positions for $\operatorname{FRAX}(\circledR)$ clinical regarding glucocorticoids: the impact of the use of glucocorticoids on the estimate by $\operatorname{FRAX}(\circledR)$ of the 10 year risk of fracture from joint official positions development conference of the International Society for Clinical Densitometry and International Osteoporosis Foundation on FRAX(®). J Clin Densitom. 2011; 14: 212-9. 